\title{
A clinical tool for evaluating complementary and alternative medicine utilization and risk
}

Keegan Guidolin (Meds 2017), Mackenzie Drew (BSc Cand)

Faculty Reviewer: Dr Michael Craig, MD, CCFP (Department of Family Medicine)

\begin{abstract}
Complementary and alternative medicine (CAM) is widely used in Canada and throughout the world, making it inevitable that family physicians will encounter CAM use in their patients. CAM therapies are highly variable and are not subject to regulation or oversight, making some such modalities potentially dangerous. Presently, CAM use is discussed during standard history taking, but the information gathered may be of limited utility due to the wide variety of CAM that exists; such diversity makes it practically impossible for one physician to know the risks associated with each CAM. Additionally, some CAM may not identified as such by the patient (eg chiropractic) and may not be reported during a standard patient interview. There currently exists no standardized method of collecting a patient's history of CAM use, or for assessing risk based on the information collected. Here, we present a clinical tool that helps to screen for use of CAM and stratify patients into risk categories accordingly. It also makes suggestions for management and follow-up of these patients according to their risk category. Included are several quick reference tables to enable physicians to rapidly stratify patients into an appropriate category. This test may help to screen patients for CAM use that puts their health at risk, thereby increasing detection, and enabling timely intervention by the physician to prevent adverse events due to CAM use.
\end{abstract}

\section{BACKGROUND}

Complementary and alternative medicine (CAM) is defined by the Canadian Medical Association and United States National Institutes of Health as "a group of diverse medical and health care systems, practices, and products that are not presently considered to be part of conventional medicine." For this reason, they are not subject to the same standards of scientific scrutiny that conventional therapies are, and consequently, many are of questionable legitimacy and safety. ${ }^{1}$ Regardless, several surveys done over the past 20 years have consistently indicated that $70 \%$ to $75 \%$ of Canadians have used CAM at least once in their lifetime. ${ }^{2-4}$ Despite the high prevalence of CAM use in the Canadian population and its ability to affect the health and safety of a patient, it can go unaddressed or undisclosed in the family physician's clinic. ${ }^{5}$

CAM can be most usefully divided into three categories: products, interventions, and practitioners. Products include items typically bought by consumers, such as herbal teas and remedies, vitamins and minerals, homeopathic remedies, traditional Chinese medicines (TCM), and many others. Interventions refer to practices such as spinal manipulation, electromagnetic field therapy, crys- tal healing, and others which may or may not involve a practitioner. Practitioners are individuals who market themselves as care providers in particular fields, such as chiropractic, TCM, homeopathy, naturopathy, Ayurveda, acupuncture, and others. Practitioners may or may not prescribe or provide both products and interventions. ${ }^{1}$

\section{CAUSE FOR CONCERN}

While some regulatory bodies exist for mainstream therapies, CAM is poorly regulated overall. ${ }^{6-8}$ Due to poor regulation and the lack of medical education of most practitioners, CAM can pose significant threats to the health of Canadians through a variety of mechanisms:

- The traditional Chinese herb ma huang contains unregulated levels of ephedrine and can cause numerous adverse effects including palpitations, hypertension, arrhythmia, nervousness, tremors, seizures, heart attack, stroke, and death. ${ }^{9}$

- Ginseng is a naturopathic remedy marketed under the name $C O L D-F X$ as an immune system booster that will prevent viral influenza and strengthen normal body function, among other such claims. Serious drug interactions with warfarin have been described, as well as stimulation of manic episodes in psychiatric patients on antidepressants. ${ }^{10}$

- Ayurvedic medicine is a form of traditional Indian medicine that stresses the use of plant-based therapies, yet Ayurvedic medicines have been shown to contain toxic levels of heavy metals; one study found that one in five Ayurvedic herbal medicine products contained potentially harmful levels of lead, mercury, or arsenic. ${ }^{11}$

- Chiropractic is an intervention which focuses on spinal manipulation therapy, often marketed as a panacea, but numerous serious adverse effects have been reported as a result of chiropractic manipulation, including stroke, neuropraxic injury, epidural hematoma, paraplegia, and fatal posterior circulation cerebrovascular accident. $^{12-15}$

- Acupuncture is a component of some TCM and involves puncturing a patient's skin with needles along so-called meridian lines to achieve therapeutic effect. Numerous systematic reviews, multi-centre trials, and prospective studies have highlighted the dangers of acupuncture, finding that it can cause pneumothorax, hepatitis C, septicemia, endocarditis, local skin infection, perichondritis, arthritis, osteomyelitis, and many less serious side effects such as hematoma, slight hemorrhage, and dizziness. ${ }^{16-20}$ 


\section{FEATURE ARTICLE}

This represents a brief illustration of the dangers posed by CAM therapies. Of course, all medical therapies carry some risk; however, in the cases of most CAM, no benefit has been shown via randomized controlled trial, making the risk-benefit calculation one-sided. ${ }^{21}$

Not all CAM poses a direct threat to health. CAM is a catch-all term which should be parsed for clarity: complementary medicine is unconventional therapy used concurrently with conventional therapy, while alternative therapy is unconventional therapy used exclusively, in place of conventional therapy. This is an important distinction because an individual using alternative medicine is, by definition, foregoing conventional treatment - this poses an entirely different threat. ${ }^{22}$ CAM such as homeopathy, crystal healing, and reiki poses no direct threat, but may prevent people from seeking appropriate medical attention.

\section{THE CAM RISK ASSESSMENT TOOL}

Numerous studies involving CAM have highlighted the need for a better method of assessing, following, and managing CAM-using patients. ${ }^{21}$ Here we present a clinical tool intended for use by the family physician, or any physician following a patient for an extended period of time. This tool represents a means of assessing patients' use of CAM and risk of associated harm, and classifies patients into categories with targeted indications for follow-up. This tool is designed to be used when taking the initial patient history for a new patient in a family practice, but may be implemented at any time.

The tool itself consists of three components: (1) a set of initial questions to determine whether or not the patient uses CAM (CAM determination), (2) a set of questions to determine the qualitative potential for harm as a result of CAM use, and (3) a set of questions to determine whether the patient uses CAM exclusively (alternatively) or alongside conventional medicine (complementarily). These question sets help to quickly and easily stratify patients into risk categories (Figure). Each question set is aimed at evaluating the use of CAM from each of the three categories (products, interventions, and practitioners). These questions are meant only to screen for CAM which the patient may not consider outside of conventional medical care. For example, patients may consider chiropractic manipulation con-

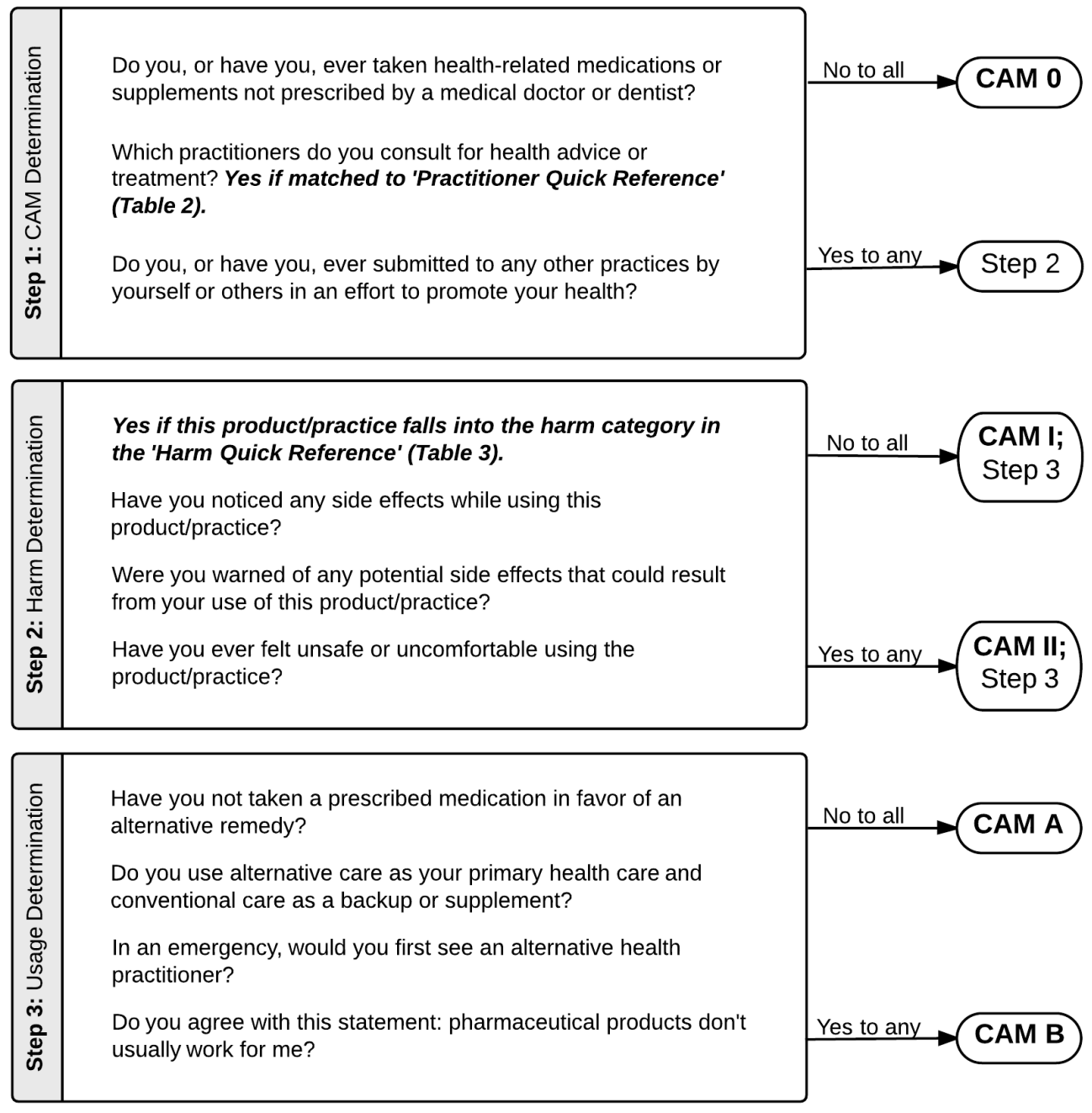

Figure: CAM risk assessment tool. 


\section{FEATURE ARTICLE}

Table 1: Summary and Indications: Class Definitions and Corresponding Management Considerations

CLASS

MANAGEMENT CONSIDERATIONS

\begin{tabular}{|c|c|}
\hline CAM O (No CAM) & - Repeat screen at periodic health assessment (PHA). \\
\hline $\begin{array}{l}\text { CAM IA } \\
\text { - Complementary } \\
\text { - Likely harmless }\end{array}$ & $\begin{array}{l}\text { - Education regarding lack of evidence for CAM. } \\
\text { - Encourage physician consultation before starting new therapies. } \\
\text { - Contact CAM practitioner, open communications regarding treatment prescribed. } \\
\text { - Works towards dispelling CAM use, move patient towards CAM class } 0 . \\
\text { - Re-evaluate at PHA. }\end{array}$ \\
\hline $\begin{array}{l}\text { CAM IB } \\
\text { - Alternative } \\
\text { - Likely harmless }\end{array}$ & $\begin{array}{l}\text { - Non-aggressive discussion recommended - trust in mainstream medicine and physicians may be tenuous. } \\
\text { - Gain patient trust. } \\
\text { - Contact CAM practitioner, open communications regarding treatment prescribed. } \\
\text { - Address immediate health concerns at physician's discretion. } \\
\text { - Follow patient closely. }\end{array}$ \\
\hline $\begin{array}{l}\text { CAM IIA } \\
\text { - Complementary } \\
\text { - Potentially harmful }\end{array}$ & $\begin{array}{l}\text { - Education regarding lack of evidence for CAM. } \\
\text { - Encourage physician consultation before starting new therapies. } \\
\text { - Contact CAM practitioner, open communications regarding treatment prescribed. } \\
\text { - Address harmful effects of CAM (eg heavy metal screen in Ayurveda use). } \\
\text { - Advise against use of harmful CAM. }\end{array}$ \\
\hline $\begin{array}{l}\text { CAM IIA } \\
\text { - Alternative } \\
\text { - Potentially harmful }\end{array}$ & $\begin{array}{l}\text { - Non-aggressive discussion recommended - trust in mainstream medicine and physicians may be tenuous. } \\
\text { - Address immediate health concerns. } \\
\text { - Gain patient trust. } \\
\text { - Contact CAM practitioner, open communications regarding treatment prescribed. } \\
\text { - Advise against use of harmful CAM only if patient is open to the idea. } \\
\text { - Pediatric: Refer to Children's Aid Society (or analogue) at physician's discretion. }\end{array}$ \\
\hline
\end{tabular}

ventional medical treatment when a physician asks. The questions are not meant to be exhaustive and follow-up questions are necessary for an adequate assessment of CAM use.

Included is a patient scoring system and score-dependent management recommendations (Table 1). These should be taken only as a list of options to consider based on the relative risk. They are not meant to be exhaustive, nor are they meant to be applied to every patient-naturally, the physician must apply the entirety of this tool on a case-by-case basis. To help simplify the application of the tool, two Quick Reference Charts are included. The first is a list of types of CAM practitioners; patients who identify any of these practitioners as someone they regularly see for health advice can be considered to use CAM (Table 2). The second is a list of CAM modalities stratified into likely harmless and potentially harmful categories based on literature review (Table 3). The use of this table helps to determine a patient's risk of harm (CAM class I vs II).

The ultimate goal of the management considerations presented by this tool is the reduction and eventual elimination of CAM use by the patient. This is theoretically achieved over multiple visits, with CAM score reassessment at each; however, particular care should be taken in a few situations. Firstly, in cases of CAM class B, or use of alternative medicine, care must be taken to avoid confrontation. Since these patients use CAM as an alternative, their trust in mainstream medicine may be tenuous, and thus, if a physician addresses CAM use too aggressively, patient trust may be lost and the patient may be lost to follow-up. Secondly, special attention should be given if a child is being treated with CAM, particularly CAM class II (po-

\begin{tabular}{ll}
\hline Table 2: Practitioner Quick Reference: List of CAM Practitioners & \\
\hline Acupuncturist & Homeopathic doctor \\
\hline Aromatherapist & Naturopath/Herbalist \\
\hline Astrologer & Osteopathic doctor \\
\hline Chiropractor & Reflexologist \\
\hline Crystal Healer & Shaman \\
\hline Holistic doctor & Traditional Chinese medical doctor \\
& \\
&
\end{tabular}

Table 3: Harm Quick Reference: Likely Harm Associated with Complementary Use of Common CAM

\begin{tabular}{|c|c|}
\hline Likely harmless $^{a}$ & $\begin{array}{l}\text { - Acupressure/shiatsu }{ }^{24} \\
\text { - Faith healing/prayer }{ }^{25} \\
\text { - Hypnosis' } \\
\text { - Magnetic healing } \\
\text { - Reiki/therapeutic touch }{ }^{28}\end{array}$ \\
\hline Potentially harmful $^{b}$ & $\begin{array}{l}\text { - Acupuncture } \mathrm{e}^{16-20} \\
\text { - Ayurvedic medicine } \\
\text { - Chiropractic }{ }^{12-15} \\
\text { - Colonics }{ }^{29} \\
\text { - Herbal supplementation }{ }^{c, 10,30} \\
\text { - Homeopathic medicine }{ }^{31} \\
\text { - Traditional Chinese medicine }{ }^{9,32}\end{array}$ \\
\hline \multicolumn{2}{|c|}{$\begin{array}{l}\text { a Harmlessness is not an endorsement of CAM effectiveness. } \\
\text { b Harm classification based on complementation of conventional care; alternative care has } \\
\text { inherent risks. }\end{array}$} \\
\hline
\end{tabular}


tentially harmful CAM). Continued use of potentially harmful CAM on pediatric patients in the face of physician advice to the contrary raises serious concerns regarding abuse, and the involvement of the Children's Aid Society and analogous groups may be indicated. Ultimately, follow-up is key in both of these scenarios, as the patient-physician relationship should be developed and leveraged appropriately to ensure the health of patients who use CAM.

\section{LIMITATIONS AND FUTURE DIRECTIONS}

The relative lack of existing research on the consideration of $\mathrm{CAM}$ as a risk factor for future medical conditions makes a tool like the one presented here inherently qualitative in nature. It is difficult to make empirical risk evaluations or evaluate the effect of the management considerations listed here in a quantitative fashion. As such, this tool is presented as a means of standardizing the CAM component of a patient history in order to act as a screen. Primarily, this tool aims to help physicians take a more complete history with regard to CAM use in their patients. Future studies may assess whether the use of this tool increases detection of CAM use in patients at the level of the primary caregiver.

\section{REFERENCES}

1. Canadian Medical Association. CMA Policy: complementary and alternative medicine [Internet]. Ottawa (ON): Canadian Medical Association; 2008 [cited 2013 Mar 31]. Available from: http://policybase.cma.ca/ dbtw-wpd/Policypdf/PD08-03.pdf

2. Fraser Institute. Complementary and alternative medicine in Canada: trends in use and public attitudes, 1997-2006. [Internet]. Vancouver (BC): Fraser Institute; 2007 [cited 2014 Apr 4]. Available from: http://www.fraserinstitute.org/uploadedFiles/fraser-ca/Content/ research-news/research/publications/complementary-alternative-medicine-in-canada-2007.pdf

3. Schnabel K, Binting S, Witt CM, Teut M. Use of complementary and alternative medicine by older adults - a cross-sectional survey. BMC Geriatr. 2014 Mar;14(1):38.

4. McFarland B, Bigelow D, Zani B, Newsom J, Kaplan M. Complementary and alternative medicine use in Canada and the United States. Am J Public Health. 2002;92(10):1616-8.

5. Robinson A, McGrail MR. Disclosure of CAM use to medical practitioners: a review of qualitative and quantitative studies. Complement Ther Med. 2004 Jun;12(2):90-8.

6. Canadian Chiropractic Association [Internet]. Toronto (ON); 2013. About Us; 2013 [cited 2014 Apr 4]. Available from: http://www.chiropracticcanada.ca/en-us/the-cca/about-us.aspx

7. Acupuncture Foundation of Canada Institute [Internet]. North York (ON); 2008. Overview; 2008 [cited 2014 Apr 4]. Available from: http:// www.afcinstitute.com/AboutAFCI/Overview/tabid/79/Default.aspx

8. The Canadian Society of Chinese Medicine and Acupuncture [Internet]. Toronto (ON); 2014. Home; 2014 [cited 2014 Apr 4]. Available from: http://www.tcmcanada.org/english/Filel.php?id=1

9. Haller CA, Benowitz NL. Adverse cardiovascular and central nervous system events associated with dietary supplements containing ephedra alkaloids. N Engl J Med. 2000 Dec;343(25):1833-8.

10. Vazquez I, Agüera-Ortiz L. Herbal products and serious side effects: a case of ginseng-induced manic episode. Acta Psychiatr Scand. 2002;105(1):76-7; discussion 77-8.

11. Saper RB, Phillips RS, Sehgal A, et al. Lead, mercury, and arsenic in US- and Indian-manufactured Ayurvedic medicines sold via the internet. JAMA. 2008 Aug;300(8):915-23.

12. Wand BM, Heine PJ, O'Connell NE. Should we abandon cervical spine manipulation for mechanical neck pain?: yes. BMJ. 2012 Jun;344:e3679.

13. Gouveia LO, Castanho P, Ferreira JJ, Guedes MM, Falcao F, e Melo TP. Chiropractic manipulation: reasons for concern? Clin Neurol Neurosurg. 2007 Dec;109(10):922-5.

14. Morandi X, Riffaud L, Houedakor J, Amlashi SF, Brassier G, Gallien P. Caudal spinal cord ischemia after lumbar vertebral manipulation. Joint Bone Spine. 2004 Jul;71(4):334-7.

15. Leon-Sanchez A, Cuetter A, Ferrer G. Cervical spine manipulation: an alternative medical procedure with potentially fatal complications. South Med J. 2007 Feb;100(2):201-3.

16. Wheway J, Agbabiaka TB, Ernst E. Patient safety incidents from acupuncture treatments: A review of reports to the National Patient Safety Agency. Int J Risk Saf Med. 2012 Jan;24(3):163-9.

17. Ernst G, Strzyz H, Hagmeister H. Incidence of adverse effects during acupuncture therapy-a multicentre survey. Complement Ther Med. 2003 Jun;11(2):93-7.

18. Norheim AJ, Fønnebø V. Acupuncture adverse effects are more than occasional case reports: Results from questionnaires among 1135 randomly selected doctors, and 197 acupuncturists. Complement Ther Med. 1996 Jan; $4(1): 8-13$.

19. Chung A, Bui L, Mills E. Adverse effects of acupuncture. Which are clinically significant? Can Fam Physician. 2003 Aug;49(8):985-989.

20. Norheim AJ. Adverse effects of acupuncture: a study of the literature for the years 1981-1994. J Altern Complement Med. 1996 Summer;2(2):291-7.

21. Ernst E. The role of complementary and alternative medicine. BMJ. 2000 Nov;321(7269):1133-5.

22. National Center for Complementary and Alternative Medicine (NCCAM) [Internet]. Bethesda (MD): National Center for Complementary and Alternative Medicine; 2014. Complementary, alternative, or integrative health: what's in a name?; 2014 [cited 2014 Apr 4]. Available from: http://nccam.nih.gov/health/whatiscam.

23. Barrett B, Marchand L, Scheder J, et al. What complementary and alternative medicine practitioners say about health and health care. Ann Fam Med. 2004 May-Jun;2(3):253-9.

24. Ernst E. The safety of massage therapy. Rheumatology. 2003 Sep;42(9):1101-6.

25. Aviles JM, Whelan SE, Hernke DA, et al. Intercessory prayer and cardiovascular disease progression in a coronary care unit population: a randomized controlled trial. Mayo Clin Proc. 2001 Dec;76(12):1192-8.

26. Webb A, Kukuruzovic R, Catto-Smith A, Sawyer S. Hypnotherapy for treatment of irritable bowel syndrome. Cochrane Database Syst Rev. 2007 Oct;17(4).

27. Pittler MH. Static magnets for reducing pain. Focus Alternat Complement Ther. 2008 Jun;13(1):5-6.

28. Lee M, Pittler M, Ernst E. Effects of reiki in clinical practice: a systematic review of randomised clinical trials. Int J Clin Pract. 2008 Jun;62(6):947-54.

29. Mishori R, Otubu A, Alleyne Jones A. The dangers of colon cleansing. J Fam Pract. 2011 Aug;60(8):454.

30. De Smet PA. Health risks of herbal remedies: an update. Clin Pharmacol Ther. 2004 Jul;76(1):1-17

31. Posadzki P, Alotaibi A, Ernst E. Adverse effects of homeopathy: a systematic review of published case reports and case series. Int J Clin Pract. 2012 Apr;66(12):1178-88.

32. Genuis SJ, Schwalfenberg G, Siy AK, Rodushkin I. Toxic element contamination of natural health products and pharmaceutical preparations. PloS One. 2012 Nov;7(11):e49676. 